\title{
Museo de la Memoria y los Derechos Humanos de Santiago de Chile: crisis de memoriales y lógicas urbanísticas de mercado ${ }^{1}$
}

El presente artículo discute el impacto producido por la inauguración en 2010 del Museo de la Memoria y los Derechos Humanos en Santiago de Chile, en el marco de la celebración del Bicentenario de la Independencia. La lectura que se propone entiende el Museo como respuesta al deseo del gobierno de la Concentración por controlar el significado del resto de memoriales de Chile, que se habían vuelto demasiado ambiguos $e$ independientes. El Museo se concibe, por tanto, como archi-memorial para controlar el sentido de los demás memoriales de Chile. Reestructura el mapa de la memoria de Santiago y, en última instancia, de todo el país, a la vez que reincide en el centralismo político. También se propone un análisis de la exposición permanente del Museo con respecto a lo excluido, tanto de la historia de otras memorias, desde el allendismo hasta el conflicto mapuche, como de la relación jerárquica entre la exposición permanente y las muestras temporales. Finalmente, se aboga por la necesidad de interpretar el Museo dentro de las lógicas del mercado urbanístico, la gentrificación y la espectacularización de la arquitectura, a partir de las políticas oficiales de reconstrucción nacional, marca-ciudad y terciarización económica de la modernidad neoliberal.

El Museo de la Memoria y los Derechos Humanos fue inaugurado en Santiago de Chile el 2010 de enero de 2010. El concurso público para su diseño se convocó en junio de 2007, resultando ganadores los arquitectos brasileños Mario Figueroa, Lucas Fehr y Carlos Dias, con estudio en São Paolo. El Museo entró a formar parte de una serie de instituciones museísticas latinoamericanas que tienen por objetivo la colección, preservación y exhibición de documentos y otros artefactos originales con los que producir un relato estatal de la memoria de los abusos a los derechos humanos perpetrados durante las dictaduras de la segunda mitad del siglo XX. Anteriores al museo chileno se establecieron el Museo de la Memoria de Rosario (Argentina), de 1998, el Espacio para la Memoria y para la Defensa de los Derechos Humanos, antigua Escuela de Suboficiales de Mecánica de la Armada (ESMA), inaugurado como tal en 
Buenos Aires en 2004, el Centro Cultural Museo de la Memoria de Montevideo, de 2006, y ya abierto después del museo chileno, el Lugar de la Memoria del Perú, inaugurado en Lima en 2011. ${ }^{2}$

La creación de estos espacios es un fenómeno global de las últimas décadas. Entre sus precedentes se hallan el Museo de los Crímenes Genocidas Tuol Sleng en Phnom Penh, inaugurado en 1980, el Museo del Distrito Seis en Ciudad del Cabo, de 1994, o los museos del Holocausto, como el Museo-Memorial del Holocausto en Washington DC., de 1993, o el Museo Judío de Berlín, de 1999. Habría que añadir el Museo-Memorial del 11 de septiembre, en Nueva York, abierto en mayo de 2014. Uno de los ejes que permite clasificar una lista tan heterogénea de museos sería la localización en un espacio directamente vinculado a los acontecimientos exhibidos en el museo. El espectro es amplio: desde museos instalados en antiguos centros de detención y tortura, como es el caso de la ESMA en Buenos Aires, hasta otros cuya localización no responde a esta sacralización del espacio, sino que son creados o bien en otros edificios o bien ex nihilo, como el Museo de la Memoria chileno.

Con sacralización del espacio me refiero al sentido etimológico que Giorgio Agamben emplea en Homo sacer: Sovereign Power and Bare Life. Se trata de espacios (no-)separados - "separación" es la palabra clave aquí en distintos momentos, o bien durante los acontecimientos traumáticos que más tarde serán rememorados, o bien más adelante, tras una transición política, por gobiernos democráticos que crean espacios de memoria. En el caso de las represiones dictatoriales, los centros de tortura eran, a menudo, no-separados del resto del paisaje urbano o rural, esto es, se trataba de edificios comunes cuyo uso se pretendía invisibilizar por un halo de cotidianidad. Es el caso de la ESMA, en Buenos Aires, y del prestigioso centro de enseñanza secundaria Tuol Svay Prey, en Phnom Penh, usados como cuarteles de tortura por las juntas militares argentinas y los Jemeres rojos, respectivamente.

Esta primera no-separación podría entenderse a través de una extensión de la noción de camuflaje en la arquitectura, a partir - y más allá - de la definición propuesta por Neil Leach. Para Leach, "camouflage is a form of masquerade, a mode of representation" (240), en la que bien un individuo, bien un edificio, se incorporan a un sistema identitario propio de una determinada comunidad; en otras palabras, es una estrategia de pertenencia a una estructura de relaciones simbólicas. El caso de estos centros de detención es distinto. El camuflaje se produce en un segundo grado: se trata de una consecuencia de la sustracción de la ley por parte de las dictaduras militares que precisan de lugares invisibilizados para proceder a la ilegalidad del secuestro, tortura y desaparición forzada de 
personas. Utilizar un espacio camuflado en el paisaje urbanístico e invisibilizar las prácticas ilegales que se producen en él.

El segundo grado de (no-)separación se produce una vez derrocada la dictadura militar, y/o tras un proceso más o menos pacífico e institucional de transición hacia un Estado de derecho. En ese momento, las fuerzas fácticas de la dictadura militar, en distinto grado según su forma de supervivencia en las estructuras estatales y sociales posteriores, pasan a ejercer diferentes prácticas de presión (institucional, financiera, vecinal) para provocar, o bien el camuflaje definitivo del edificio o conjunto arquitectónico a través de la redefinición de su uso y el silenciamiento de su historia, o bien su invisibilización definitiva, su destrucción. El propósito de ambas prácticas se sitúa más allá del olvido: se trata de la negación.

Hay en Santiago dos casos paradigmáticos en este sentido: Londres 38 y Villa Grimaldi. Londres 38 fue usado por la Dirección de Inteligencia Nacional de la Dictadura (DINA) como centro de detención y tortura. Se le conoció como Cuartel Yucatán. Su historia es la de la pugna continua por su camuflaje e invisibilización: cuando la localización del centro trascendió esto es, se visibilizó -, aún en dictadura, los responsables cambiaron el número de la casa. Del 38 pasó a ocupar el 4o. El edificio, situado en la calle Londres del centro de Santiago, se desplazó simbólicamente, sin que otro edificio ocupara el número 38 , constituyéndose así un vacío, una grieta, una incisión, en el plano urbano de la ciudad.

El caso de Villa Grimaldi es de otra naturaleza. Se trata de una finca situada en la comuna de Peñalolén, que en el siglo XIX había servido de centro cultural regentado por el abogado Juan Egaña. Fue allanada por los militares el día después del golpe de Estado y utilizada desde entonces como centro de detención y tortura bajo el nombre de Cuartel Terracota. Muy activo durante los primeros años de la dictadura, el Cuartel Terracota llegó a contener 4500 detenidos, entre los cuales se encontraba la actual presidenta del país, Michelle Bachelet, junto a su madre. 236 de ellos desaparecieron definitivamente. A partir de finales de los 70, el centro cae en desuso y la ruinificación planificada se va completando hasta la transición democrática. El recinto fue adquirido por la Sociedad Constructora EGTP Ltda., propiedad de familiares de Hugo Salas Wenzel, el último director del Centro Nacional de Informaciones (CNI) pinochetista, que demolió los distintos edificios de la finca con el fin de proporcionar argumentos al negacionismo. No existe, no hay pruebas, no ocurrió. Pretendía borrar las huellas de la tortura y los abusos al incorporar el espacio al mercado inmobiliario a través de la construcción de un complejo residencial. Hacer desaparecer el lugar en que se hizo desaparecer, sepultar con la desaparición las huellas de la desaparición. 
El derribo se llevó a cabo, pero un movimiento vecinal organizado en torno a la Asamblea Permanente por los Derechos Humanos de Peñalolén y La Reina consiguió paralizar el proyecto de invisibilización. El Estado expropió la finca y en marzo de 1997 se abre al público como Parque por la Paz Villa Grimaldi. ${ }^{3}$ Esta es la segunda separación-visibilización referida anteriormente, la de los gobiernos democráticos convirtiendo ciertos espacios en lugares de memoria. Del camuflaje de segundo grado en los primeros años de la dictadura, a la ruina de los 8o, el intento de supresión definitiva con la democracia, y la recuperación final tan solo del suelo y los cimientos como borradura de la memoria, reivindicada primero por asociaciones de vecinos, y finalmente incorporada a la oficialidad estatal.

El Museo produce una intervención en el mapa de la memoria de Santiago y, por extensión, de Chile, y lo hace en un momento capital en América Latina para las discusiones activistas y académicas sobre los lugares de memoria, siguiendo los estudios de autores que se han preocupado por la permanencia de las prácticas memorísticas en un mundo volcado al futuro: tal es el caso de Pierre Nora (Les Lieux), ${ }^{4}$ quien entiende estos lugares como remanentes rituales en un mundo desritualizado; o Andreas Huyssen, quien estudia las sociedades posmodernas a través de su fijación con la memoria, y la forma en que ésta ha producido nuevos memoriales y museos que han transformado el espacio urbano. ${ }^{5}$

Hay varias políticas estatales para articular el pasado, entre ellas la creación de instituciones museísticas y galerías. La producción de espacios de la memoria, como Villa Grimaldi o Londres 38, precedió en el tiempo a la creación del Museo por la urgencia de frenar las operaciones que pretendían hacer desaparecer esos espacios. Pero hay otra diferencia, pues estos espacios nacen indefectiblemente desde abajo, a partir de la presión de grupos vecinales y de preservación de la memoria de la dictadura en algunos casos buscando un discurso disruptivo con respecto al relato oficial de la reconciliación como olvido. ${ }^{6}$

En cambio, el Museo posee una naturaleza diferente, casi opuesta a estos otros espacios de memoria en algunos sentidos. Es una institución estatal, ya proyectada y anunciada por Michelle Bachelet al inicio de su primera magistratura, pero que no se llevó a cabo hasta los últimos dos años de la misma. Es un espacio de memoria que nace desde arriba, evitando explícitamente la confrontación pública. El proceso legal así como el concurso arquitectónico y la construcción misma del edificio y la plaza que los circunda fueron fugaces. El perfil fue bajo, discreto, para neutralizar cualquier debate público ampliamente abierto y potencialmente crítico. El objetivo era erigir el Museo en un período de 
tiempo récord en un momento que se advertía inseguro o, en palabras de Walter Benjamin, en un instante de peligro (255).

2010 fue un año de profundas incertidumbres y de notable revisionismo histórico en Chile. Junto al terremoto natural de magnitud 8,8 que asoló el país se produjo un terremoto político: el retorno de la derecha al gobierno, en un régimen democrático. Además, se trataba del año de celebraciones del Bicentenario de la Independencia. En ese marco de fastos hay que situar el Museo. Este es un Proyecto Bicentenario, ligado al gobierno de centro-izquierda de la Concertación en general, y al de Michelle Bachelet en particular, pues el objetivo fue siempre inaugurarlo dentro de su magistratura. El peligro era poliforme: de un lado, se debía a la crisis de los monumentos y memoriales de signo diverso que habían proliferado por todo el país; de otro, y fundamentalmente, era una pugna por un relato de la historia, con Michelle Bachelet como divisa de la reconciliación, el consenso y la estabilización democrática como valor axiomático.

Todo esto ocurría una vez que la Concertación predecía que su continuidad en el poder podía tener fin en las próximas elecciones. En este sentido, el Museo de la Memoria y los Derechos Humanos propone uno de los relatos posibles de la dictadura, que no se corresponde siquiera con el de la izquierda en un sentido amplio, ni con el activismo ciudadano o vecinal. Se trata del relato institucional de la Concertación.

MUSEO DE HISTORIA VS. MUSEO DE MEMORIA

El Museo de la Memoria y los Derechos Humanos de Santiago pone en cuestionamiento su relación con la historia al presentarse como un museo de memoria. La problematización entre historia y memoria se halla, como ya quedó señalado, en el centro de la caracterización de lo que Nora ha llamado lugares de memoria. Para Nora, estos espacios producen dos movimientos simétricos y simultáneos: en primer lugar, el repliegue de la historia sobre sí misma, esto es, un giro historiográfico; en segundo, el movimiento puramente histórico de la interrupción de la tradición memorística. Nora relata el reemplazo y clausura de la memoria, múltiple e individual, y al mismo tiempo sagrada, absoluta, por una ciencia social historiográfica que pretende instaurarse como "verdadera memoria" ("Between Memory" 8-9). En ese momento de sustitución, que en Occidente puede datarse en torno a la crisis de los años 30, comienzan a proliferar los lugares de memoria como instrumento de vigilancia conmemorativa para un cuerpo social que se ha vuelto amnésico. A partir de este contexto y como inscripción crítica dentro de él, puede leerse la operación política efectuada por el Museo. 
Dentro de los lugares de memoria estatales, el Museo de la Memoria y los Derechos Humanos pertenece, a pesar de sus notables diferencias, a la tradición de los museos del Holocausto que se han inaugurado en las últimas décadas en distintos lugares del mundo. Quizás el más representativo al respecto sea el Museo-Memorial del Holocausto en Washington DC. ${ }^{7}$ Su primer presidente, Michael Berenbaum, con motivo del catálogo que se publicó para la inauguración del mismo en 1993, The World Must Know. The History of the Holocaust as Told in the United States Holocaust Museum-Memorial, lo presentó de la siguiente forma:

The museum has been built to tell America and the world the factual story of this most terrible event in modern history, and to illuminate the crucial moral lessons it entails ... . The museum does not undertake to explain why the Holocaust has happened. This question has yet to be answered by the historian, and it is doubtful whether such answer will ever go beyond the limits of unprovable hypothesis and speculation. (xiv)

He aquí varias características fundamentales de este tipo de museos: en primer lugar se trata de un museo de certezas, post-histórico, en el sentido de venir después de cualquier reflexión histórica que ya ha fijado los datos de lo que aconteció e identificado ciertas cuestiones como irresolubles. ${ }^{8}$ Por tanto, proclama que la dimensión de su intervención no es histórica, sino de memoria, donde esta refiere, por un lado, al relato oficial del Estado y, por otro, a una moral. Asimismo, reinstaura una fe absoluta en el testimonio seleccionado, en el lenguaje y en la mirada del testigo, pues "only a survivor of the Holocaust can fully know and understand what happened in those terrible years" (Berenbaum xv; énfasis añadido). Un Museo-Memorial donde la memoria es unívoca, cribada y monopolizada; un presente que ha seleccionado lo legible del pasado y ha decidido dejar fuera lo (aún)-no-legible o lo potencialmente debatible.

Hanna Arendt promulgaba "the deadly impact of new thoughts" (201) para aproximarse al Holocausto como pasado, es decir, un camino liberado de los patrones y modos tradicionales en el quehacer histórico y crítico. El Estado se formuló asimismo tal cuestión y su respuesta se materializó con este deshacerse de la tradición historiográfica-museística para crear una nueva donde lo que se sitúa en el centro son los hechos cuantificables y el consenso. Es en esta tradición donde se inscribe el Museo de la Memoria y los Derechos Humanos de Chile.

El Museo chileno propone sin duda un relato unívoco, el de la Concertación, que busca convertir en estatal su propio relato de la dictadura. Puede leerse a partir de tres pilares fundamentales: moral, 
consensual e identitario. En cuanto al pilar moral, y en sintonía con los museos del Holocausto, es un museo sobre la destrucción y el "mal" en tanto principio moral inexcusable e irrepetible durante un período preciso de la historia chilena. Aunque su nombre anuncia el tratamiento de valores universales como la memoria y los derechos humanos, la exhibición permanente se centra en un paradigma del mal, el de la dictadura pinochetista. Una de las tareas que se propone el Museo es la de la educación moral de la ciudadanía.

No se trata de un museo de postmemoria, en el sentido pergeñado por Marianne Hirsch, ya que no es la generación posterior a los acontecimientos la que trata de producir sentidos a la memoria individual, colectiva y cultural. Más bien al contrario: produce sentidos dicotómicos y nítidos para esa generación posterior y las siguientes. Además, el productor de sentido es un gobierno que fue protagonista de los acontecimientos presentados: la figura de Michelle Bachelet es paradigmática. Se trata de $s u$ Museo, proyecto anunciado al principio de su magistratura y que debía de estar concluido antes de que abandonara el cargo. Ella lideró la procesión de expresidentes de la democracia que inauguró el recinto. Bachelet es el símbolo de la militante de izquierdas torturada por las fuerzas de inteligencia y represión pinochetistas, exiliada y retornada para incorporarse al nuevo régimen democrático del país y convertirse finalmente en presidenta. El horizonte cumplido de la reconciliación y la transición.

Además del símbolo del consenso político, Bachelet lo es también de la paz con el Ejército. Es hija de Alberto Bachelet, militar de alto rango fiel a Salvador Allende, Director Nacional de Abastecimiento y Comercialización durante el mandato de este, hasta que fue detenido por las fuerzas de la Junta Militar. Falleció en prisión. Así pues, ella fue Ministra de Defensa Nacional (2002-04) durante el gobierno de Ricardo Lagos, antes de asumir la presidencia del país. La hija del militar represaliado que termina siendo Ministra de Defensa. Nora considera que algunos historiadores se han convertido ellos mismos en lugares de memoria ("Between Memory" 18); dentro de este fenómeno puede pensarse a Bachelet, que se presenta como historia de reconciliación.

El gobierno produce una historia oficial incorporando algunos relatos de otras memorias de activistas y organizaciones por los derechos humanos, así como de proyectos críticos y artísticos, pero sin dejar de aferrarse al régimen transicional de 1988-90. El Museo no es una plataforma para la discusión historiográfica o ideológica. Es un museo para mostrar los hechos consensuados por la larga transición democrática para reafirmarlos en una repetición continua y para educar a las jóvenes 
generaciones y visitantes extranjeros en el mismo relato. Siguiendo a Nora, estos museos rechazan su parangón con los museos históricos en que la historia ha perdido la autoridad pedagógica para convertirse en instrumento transmisor de valores. Su objetivo ya no es sustentar una identidad nacional, sino conseguir la paz y la prosperidad ("Between Memory" 11), o, en los términos empleados en Chile, la reconciliación y el consenso.

Esta dimensión de la educación en el consenso es particular del Museo de la Memoria chileno con respecto a los museos del Holocausto. En estos últimos, las diferencias son sustanciales si tal museo se encuentra en Alemania, Israel, Estados Unidos o América Latina, en particular a partir de las distintas historias nacionales de aniquilaciones de grupos étnicos determinados, y las políticas étnicas y raciales. Berenbaum, en lo referente al Museo-Memorial de Washington DC, afirmaba lo siguiente: "The history described here cuts against the grain of the American ethos. We learn of evil unredeemed, of death, of destruction. The Holocaust offers no happy ending, no trascendent meaning, no easy moralism" (2). El MuseoMemorial del Holocausto dice buscar la desestabilización de las certezas del visitante en su posición moral y ética. Lo hace apuntando directamente a la culpa del testigo no afectado directamente por la represión planteando lo siguiente:

how they would have behaved in the position of a witnessing bystander. The understanding of the passive bystander's inadvertent guilt is probably the most important and most relevant moral lesson the museum can teach its visitors. Its importance lies in its applicability to contemporary historical and social phenomena as well as to occurrences in everybody's daily life. (xv)

El Museo chileno es opuesto en este sentido. Si el Museo-Memorial del Holocausto dice buscar que el visitante se sienta cuestionado, el Museo de la Memoria pretende que el visitante se reafirme en sus certezas democráticas, en el discurso oficial de la transición política. De esta forma, se presenta a sí mismo, y no solo en la retórica oficial de su presentación, sino también desde la curaduría, como un final feliz.

La exposición permanente abre con las turbulencias sociales, vagamente referidas, al final del gobierno de Salvador Allende y el golpe de Estado. Tras recorrer a través de varias galerías y espacios todos los acontecimientos más oscuros de las prácticas de violencia, represión, asesinato y desaparición de la dictadura, desemboca en la tercera y última planta, la más luminosa, con el relato de la transición democrática en tanto gran fiesta nacional. En esa tercera planta, como clausura del recorrido 
museístico, un video muestra los actos del día 12 de marzo de 1990 en el Estadio Nacional que llevaron por nombre "Así me gusta Chile", donde se celebraba la reconciliación y el consenso aún por construir.

"Así me gusta Chile" supuso el bautismo del Estadio Nacional como primer lugar de memoria proclamado por el nuevo régimen democrático, así como la oficialización de la fórmula del presidente Patricio Aylwin que estructuraría la política estatal chilena desde entonces hasta la creación del Museo: "verdad y justicia en la medida de lo posible para la historia pasada, reencuentro y reconciliación de cara a la historia del futuro. Y en medio, la figura del Presidente, el valedor de la patria justa y buena" (Otano 131). El final feliz del consenso y la reconciliación. Los abusos acabaron en fiesta y desde esa fiesta se conmemoran la destrucción y el horror que no han de volver a cobrar protagonismo. El Museo es performático en ese sentido, una repetición de esa celebración de la transición, un eslabón en un bucle infinito de conmemoraciones, donde la justicia de lo posible sigue cifrada en el simbolismo de lo que queda fuera. En ese sentido, el Museo de la Memoria es también el museo de lo que el gobierno de la Concertación no puede discutir en profundidad hoy día en Chile.

Alberto Moreiras planteaba unos años antes una pregunta de gran relevancia también para el Museo: "¿denuncia o renuncia?" (315). El papel del olvido en la construcción de las naciones fue notablemente apuntado por la filosofía de la historia decimonónica. Piénsese en el Nietzsche de Unzeitgemässe Betrachtungen. Vom Nutzen und Nachteil der Historie für das Leben (1874) o en el Renan del célebre discurso Qu'est-ce qu' une nation? (1882). El olvido de la violencia originaria se consideraba conditio sine qua non para la construcción de una identidad nacional. Asimismo, el Museo se planteó desde un principio como un proyecto de (re)construcción nacional, siendo parte de la celebración del Bicentenario de la Independencia, además de coincidir fortuitamente con el terremoto. La pregunta que cabría formular es quién y cómo se olvida colectivamente en el siglo XXI a diferencia del XIX, es decir, cómo se olvida en el Bicentenario, en una sociedad democrática, alfabetizada, y donde los sucesos históricos en cuestión han sido protagonizados por las masas; hay que apuntar hacia la historización del olvido y sus tecnologías estatales.

Moreiras se preguntaba “¿denuncia o renuncia?" en relación a la carta enviada por el entonces instructor de la Universidad de Duke en Estados Unidos, Felipe Agüero, a la Universidad Católica de Chile y en noticia difundida por diversos medios de comunicación. En ella, Agüero acusaba a uno de los profesores de esta última, Emilio Meneses, de haber participado en el escuadrón militar que lo torturó en el Estadio Nacional durante los 
días posteriores al golpe de Estado de 1973. Agüero vivía en Estados Unidos desde 1982. Reconoció a Meneses en un congreso en Santiago en 1988, aunque la carta no fue publicada hasta 2001. Es precisamente este silencio de trece años el que es objeto de reflexión para Moreiras. ¿Por qué tanto tiempo para denunciarlo, si la mayor parte de él transcurrió en democracia? Para abordar tal cuestión, Moreiras propone una lectura a partir de la noción de secreto público, tal y como la entiende Michael Taussig:

Esta negatividad de saber qué no-saber está en el corazón de una vasta cadena de poderes sociales y de conocimientos relacionados con esos poderes de modo que el desmañado híbrido del poder/conocimiento viene a cobrar sentido, a saber, no que el conocimiento sea poder, sino que el activo no-saber lo convierte en tal... Sin tales secretos compartidos, todas y cada una de las instituciones sociales... fracasarían. (Taussig cit. en Moreiras 6-7) ${ }^{9}$

Moreiras relaciona la carta pública de Agüero, con un retraso de trece años, a la fractura del secreto público chileno a partir de un proceso judicial extraterritorial: la detención de Augusto Pinochet en Londres, procesado por el juez español Baltasar Garzón bajo acusaciones de violación de los derechos humanos y crímenes contra la humanidad, y amparándose en el principio de universalidad de la justicia. La detención de Pinochet funcionó como un hito que pudo desplazar los límites del secreto público chileno y propiciar una nueva política estatal de la memoria y el olvido. No obstante, la pregunta de Moreiras apuntaba hacia un escepticismo que el tiempo y la resolución final del caso terminaron de justificar.

¿Constituye el Museo de la Memoria un nuevo hito en las políticas estatales de memoria y olvido? En caso afirmativo, ¿de qué naturaleza? ¿Cambia de forma alguna la dimensión de lo posible en el discurso estatal sobre la memoria y el olvido? ¿Produce algún desplazamiento, alguna revelación o nuevo ocultamiento en el seno del secreto público? ¿Cuáles son los (¿nuevos?) límites de ese secreto?

El texto de Moreiras está incluido en la obra conjunta Pensar en/la post-dictadura, editada por Nelly Richard y el propio Alberto Moreiras. La propuesta era problematizar el término postdictadura y el pensamiento generado en ese contexto para cifrar la naturaleza del período posterior a la primera celebración de elecciones abiertas a los partidos políticos, y en clara oposición a la nomenclatura de la transición. A este respecto, y como queda dicho anteriormente, el Museo se muestra como una repetición de la celebración de 1990, donde rupturas como la detención de Pinochet 
quedan incorporadas en forma de cita, pero no modifican de forma sustancial el discurso de justicia dentro de lo posible de Aylwin. El límite sigue siendo 1973 .

El Museo continúa en la senda de los Museos del Holocausto en la medida en que su horizonte es el de los derechos humanos y el relato de las víctimas en cuanto víctimas totales. Lo que queda fuera, lo que continúa siendo un secreto público, lo imposible de la justicia sigue siendo la política, las causas que condujeron al golpe de Pinochet. El gobierno de Allende y su fin por el golpe militar son en el Museo tan solo un estruendo inarticulado y caótico al inicio de la exhibición. Están representados por unas siluetas inidentificables en la pared, enfatizadas por un audio donde se escuchan gritos, carreras y exaltación. Una suerte de violencia original inexplicada e inexplicable, antes de subir las escaleras que llevan al punto de arranque de la muestra, el 11 de septiembre de 1973. Ese estruendo es ambiguo, aún más por su situación en las escaleras de acceso al inicio de la muestra: $i$ se trata del golpe o del pre-golpe, reflejando de modo alguno el gobierno de Allende? ¿Cómo distinguir partes dentro de un estruendo?

LO IMPOSIBLE DE LA JUSTICIA

Una de las críticas que la derecha ha pronunciado con respecto al Museo es precisamente la limitación temporal, el 11 de septiembre de 1973 como punto de partida. El imaginario de la violación de los derechos humanos es compartido y en gran medida aceptado por los sectores conservadores de la sociedad chilena. No así la evaluación general del régimen pinochetista, que aún amplios sectores apoyan, basándose en los logros de Pinochet por frenar el comunismo y potenciar el desarrollismo económico. Para estos sectores pro-pinochetistas, ampliar los límites de la exhibición al gobierno de Allende sería una oportunidad para estructurar un discurso de justificación y de ampliación de la violación de los derechos humanos al gobierno socialista. Richard apunta a esta postura:

La función de un Museo de la Memoria y los Derechos Humanos no es la de cotejar estos relatos entre sí para tratar de establecer alguna verdad equilibrada de los hechos, ni tampoco la de repartir parejamente créditos de validez que igualen la condición de verdad de los relatos históricos de signo contrario que enmarcan las visiones del golpe de Estado, sino la de condenar taxativamente lo sucedido en Chile desde una perspectiva de conciencia que, frente al pasado vergonzoso y sus abominaciones, no admita la relativización del mal. (Crítica 239)

Esa potencial ampliación de la violación de los derechos que terminaría relativizando el mal de la represión sistemática de la dictadura es una de 
las batallas ganadas al pacto de consenso de la transición o de la postdictadura, por emplear el término de Richard y Moreiras, en el volumen que co-editaron en 2001. En el Museo, la única forma de violencia por parte de la izquierda representada en la muestra permanente son los paneles informativos con documentos e imágenes del atentado contra Pinochet perpetrado en el Cajón del Maipo el 7 de septiembre de 1986 a manos del Frente Patriótico Manuel Rodríguez, grupo guerrillero marxistaleninista. El límite del 11 de septiembre de 1973 funciona como un cortafuegos que impide a la derecha pro-pinochetista incorporarse al relato de las víctimas. La otra consecuencia de esto es que, además, el allendismo como opción política nunca termina de ser incorporado, queda fuera de los límites posibles del discurso oficial, engrosando la espesura del secreto público chileno.

El Museo propone la estabilización de la memoria de la Concertación como memoria institucional. Es cierto que durante los años de gobierno de Sebastián Piñera (2010-2014) la colección permanente continuó estable y que el Museo siguió funcionando sin demasiadas presiones institucionales. ${ }^{10}$ Esto es posible gracias a varias prácticas: de un lado, los veinte años de política institucional de memoria y olvido de la Concertación. De otro, el museo funciona como culminación parcial de una etapa de estas políticas que, además, produce una invisibilización. Si el relato creado por el museo apunta al final feliz de la transición democrática y la reconciliación, el museo obvia y oculta la ausencia de consenso social en torno a la condena sin paliativos de la dictadura y, en cierta medida, convierte a la base social pro-pinochetista aún existente en parte del secreto, si no público, sí institucional.

El Museo se ha convertido en una herramienta fundamental para la fijación de un lenguaje oficial de la memoria. En esto concuerda también con los otros museos del Holocausto. Berenbaum, por ejemplo, entiende el Museo-Memorial de Washington DC como un museo conceptual (xiv), dado que entre sus principales fines está la consolidación a través de la representación visual y documental de lo que a juicio de los responsables de la curaduría la historia ha determinado ya como verdades incontestables. Los Museos del Holocausto definieron "Holocausto" de forma definitiva, clausurando el término. El Holocausto como un tipo de genocidio cuya víctima lo es siempre de forma total, en particular los millones de judíos asesinados por el régimen nazi. Asimismo, en el caso del Museo-Memorial estadounidense, tuvieron que definir "guerra", los inicios y el fin de la Segunda Guerra Mundial, el inicio y fin de los abusos represivos sistemáticos al pueblo judío por parte de instancias estatales, así como a otras minorías. Además de definir quiénes fueron los 
participantes y los cómplices de tal guerra, incorporando a Estados Unidos y al bystander, respectivamente, haciéndoles responsables en diferente medida.

El caso del Museo chileno es similar: proporciona una definición institucional de memoria, de dictadura, de transición y de represión. Ya queda señalada la propuesta de Richard y Moreiras en torno al término postdictadura. Parten de la necesidad de templanza en el lenguaje durante el proceso transicional con el fin de evitar la repetición de antagonismos irreconciliables como los causantes del conflicto que derivó en el golpe de Estado y la posterior dictadura. Para Richard, el "post-" tiene la deficiencia de coincidir con los discursos de cierre de la historia del fin del milenio; como ventaja principal apunta a la transición como una sutura excretante de lenguajes:

retiene el eco de una nominalidad sombría que nos recuerda la opacidad conflictiva, el atormentado residuo que el dispositivo simbólico (y también lexical) de la "transición" quiso borrar para que no perdiera la lisura y transparencialidad de los nuevos signos de la democracia liberal. (Richard, "Introducción" 10)

Richard ha continuado este proyecto crítico de acuñar términos que respondan al conflicto lingüístico abierto de la democracia chilena. En Crítica de la memoria (1990-2010), contemporáneo a la inauguración del Museo, Richard emplea el término postransición en el siguiente contexto:

La mera sucesión cronológica entre el antes (dictadura y transición) y el después (transición y postransición) describe un tiempo simple que sólo deja conforme a la historia lineal, mientras que el tiempo de la interpretación entre el ya-no (pasado) y el todavía-no (futuro), que se nutre de la coexistencia de lo disímil, es un tiempo compuesto: el tiempo de un presente expuesto a los saltos y desfases de una linealidad quebrada. (15)

Entiendo que con postransición se refiere aquí al nuevo período abierto tras la victoria en las elecciones de la derecha encabezada por Sebastián Piñera, para la que la transición es un período de dos décadas de gobierno de la Concertación, fuerza deficiente y amortiguada de las izquierdas reprimidas durante el gobierno de la Junta. El quiebre lingüístico lo es de naturaleza temporal donde el ya-no pasado y el todavía-no futuro refieren la insuficiencia y desvirtuación de un proyecto de izquierdas atemperado, e inciden en el allendismo y su herencia como secreto público. 
EL MEMORIAL BAJO SOSPECHA. CRISIS DE MONUMENTALIDAD

El Museo responde a una crisis de monumentalidad producida por la desconfianza institucional en los memoriales que han proliferado por toda la geografía chilena. Los últimos gobiernos de la Concertación van identificando la necesidad de un discurso centralizado que contextualice estos memoriales, los fije a un relato histórico oficial y los cribe de cualquier desliz que ponga de manifiesto la precariedad del secreto público. Los memoriales se han vuelto peligrosos.

Una muestra: en Villa Grimaldi celebran a los grupos de izquierda reprimidos por separado, haciendo que la víctima deje de ser total para ideologizarse. Una sucesión de nichos conmemorativos se halla junto a la piscina donde se bañaban los familiares de los militares represores los domingos y donde se torturaba por las noches a los detenidos. Por otro lado, y como inercia activa del boom de la memoria, la derecha se ha incorporado a las políticas públicas de memoriales. En 2008, durante el gobierno de Michelle Bachelet, y dos años antes de la apertura del Museo de la Memoria, se inauguraba el Memorial a Jaime Guzmán, de enormes dimensiones, situado frente a las colonias de clase alta Las Condes y Vitacura, y frente a la Embajada de Estados Unidos.

Jaime Guzmán fue un político pinochetista, redactor de la Constitución de 1980, líder del proceso de transición a la democracia. El 1 de abril de 1991 fue asesinado por militantes del Frente Patriótico Manuel Rodríguez. En 2008 se inauguró un monumento a su memoria promovido por la Fundación Jaime Guzmán y la Corporación Pro-Memorial Jaime Guzmán, avalado por el Estado. Se trata de un monumento público, Ley 19.205, de 1993. La presencia de este memorial re-significa en cierta medida el resto de memoriales esparcidos por todo el país. Steve Stern, en su trilogía sobre las políticas de memoria y olvido en Chile, The Memory Box of Pinochet's Chile, muestra como la derecha se incorpora a los relatos de la memoria desde el principio. No obstante, es una memoria diferente:

During the 1970s and 1980s (as seen in Book II of this trilogy), memory of military rule as salvation of the country from ruin and civil war, and its transformation into an orderly modern society of prosperity, competed for influence with memory as cruel rupture, the "open wound" of letal state terror - killings and disappearances at the margins of law, profoundly aggravated by secrecy and misinformation to cover up the crime. The salvation narrative also came to compete with another dissident framework, memory as a narrative of multifaceted persecutions that sparked a new awakening. (377-358) 
La diferencia con la erección del memorial a Jaime Guzmán, ya en los 9o, es que la derecha se adhiere a una memoria no basada en argumentos económicos o de progreso, al fantasma comunista, sino a un terrorismo político si bien no de Estado, sí marxista-leninista, ligado a la memoria del allendismo y de los gobiernos de la Concertación. Así pues, la crisis significativa de los memoriales chilenos no se debe sólo al boom que produjo su proliferación desmedida, sino a la ambigüedad que adquieren una vez que la derecha se ha incorporado a esa memoria del terror, a la desideologización y la despolitización que alcanzan un extremo intolerable para el estrecho margen en que se mueven las políticas estatales de la memoria y el olvido promovidas por la Concertación.

La Concertación no puede incorporar al allendismo, pero tampoco igualar sus víctimas a las de la derecha. Esa fina franja sub-política se juega en la representación. En ese sentido, la proliferación de memoriales puede leerse como una ansiedad donde alguno de sus componentes ha mutado. En Chile ya no hay espacios de la memoria; hay una neutralización de esos espacios - se podría hablar de la historia de los espacios de la memoria en Chile - y un museo que los sobrepasa centrípetamente para fijar la verdad oficial de la Concertación, una verdad relativamente tolerable para la derecha y que, además, esconde el disenso activo de esta con respecto a la condena total de la dictadura. Asimismo, el centralismo que determina la estructura político-económica del país se evidencia también en el mapa nacional de la memoria que el Museo funda.

Esto es palpable en la muestra permanente. Justo al entrar, en el recibidor, se encuentra una instalación que invita a una lectura metamuseística en forma de clave de interpretación del Museo. Está dividida en dos secciones: de un lado, un mapamundi acompañado por leyendas que representan a países donde también se han establecido Comisiones de Verdad, Justicia y Reconciliación. De nuevo, el discurso de la universalización como modo de legitimación. La otra sección muestra sobre el suelo una roca larga y estrecha que representa el mapa físico de Chile, sobre el que están clavados setenta y ocho estandartes que se identifican con todos los memoriales levantados por el país, desde Arica en el extremo norte a Punta Arenas en el sur, explicados uno a uno. Ninguno de ellos es un museo. Son espacios como estaciones de trenes o sedes de partidos políticos perseguidos por Pinochet, monolitos, cementerios, puentes, esculturas, parques, casas, estadios. El Museo los aglutina, los contiene y los sobrepasa. Inmediatamente después la exhibición se inicia cronológicamente con los barullos del allendismo y el golpe.

Así pues, el Museo de la Memoria funciona como significante cuasivacío que sutura una red de equivalencias, en el sentido de Ernesto 
Laclau." Al igual que el del Holocausto en Washington DC, podría entenderse como un Museo-Memorial, o Museo-Archimemorial, piedra angular que contiene y explica el resto de memoriales chilenos, con una verdad de la memoria confeccionada a la medida de la Concertación y el consenso de mínimos con la derecha, incluyendo el disenso de parte de esta en torno al relato histórico. Esto es, una verdad de la memoria que incluye como secreto a aquel sector social que la niega.

Es la Concertación, como ya queda dicho, la principal interesada en no recuperar para la memoria oficial los acontecimientos previos al golpe. Por eso, la escalera de acceso a la exhibición se inicia con el barullo de los disturbios, sin que haya espacio físico en el museo para una incorporación del "antes de". La lectura en términos laclausianos cobra mayor sentido en su mediación como productor de discursos identitarios estereotipados (piénsese, por ejemplo, en las cubiertas de cobre de la estructura del museo) y en su apuesta lingüística: el Museo desconfía de la arquitectura conmemorativa, gira hacia la exposición y propone una vuelta a un lenguaje, también de mínimos, que pretende restaurar el orden que la vaguedad del gesto arquitectónico ha pervertido.

Con respecto a la muestra permanente, el Museo es escaso en objetos y prolijo en textos. Como tecnología de la memoria, revela cierta fe en el documento, el archivo y la letra escrita. Se trata de una pretensión de gesto historiográfico a través del archivo escrito, de tal forma que la memoria de la Concertación quede justificada en la supuesta objetividad de los textos, oscureciendo la curaduría. Esta doble tendencia, de desactivación arquitectónica y re-activación textual, es patente en el diseño. El edificio es una estructura prismática mínima con cierta estética de catacumba: hay que descender a una plaza, para poder ascender al museo y entrar. En su interior está constituido por dos espacios fundamentales: el archivo con todos los documentos oficiales referentes a la represión de la dictadura, y las salas de exposiciones. El archivo está en el entresuelo, bajo tierra y sobresaliendo. Constituye los pilares del gran prisma translúcido y verdoso que conforman las salas de exposición. Este gran prisma se encuentra levemente sostenido por el espacio archivístico, produciendo un efecto de suspensión reforzado por las piscinas que lo rodean. Una forma arquitectónica mínima y unas salas de exposición explicativas y didácticas apoyadas sobre un archivo, bien anclado en la tierra, que ejerce de autoridad.

La representación de esta disponibilidad de un archivo que durante tantos años ha sido opaco es, no obstante, contradictoria. El museo presenta en su propia estructura y diseño arquitectónicos un discurso cuestionable de la transparencia. Los archivos situados en el entresuelo y 
bajo tierra funcionan como raíces desmesuradas que anclan el relato a la tierra y que producen una exhibición luminosa pero no menos opaca. Los vidrios verdosos que forman el prisma permiten sólo intuir la estructura, pero no ir más allá. Desde dentro, por contra, la sensación es de gran diafanidad. Las piscinas que lo circundan no hacen sino enfatizar la petrificación de un espacio resplandeciente en el interior, pero velado cuando es visto desde fuera. En términos de luminosidad y nitidez lo comenta también Richard (Crítica 265-66), quien emplea la definición de vidrio proporcionada por Jean Louis Deotte como una superficie reacia a la fijación de las huellas mnémicas.

El resultado es un Museo no de la dictadura, sino del presente, de un presente de vigilancia conmemorativa, de rituales incentivados. La coyuntura de la inauguración del Museo - 2010, del inicio de la postransición - está marcada por la necesidad de mantener el pacto consensual de 1990 - a pesar de las grietas -, lo que determina qué parte del archivo pasa a la exposición y qué parte queda relegada u olvidada. Un museo que se conmemora a sí mismo, su presente institucionalizador y su ficción de veinte años de poca movilidad en lo que a política oficial de la memoria y olvido se refiere.

No obstante, el ilusorio horizonte del consenso que el Museo confecciona experimenta quiebres sucesivos. Frente a las tecnologías y performances de la memoria estatal, otras memorias subterráneas, otros colectivos, otras prácticas y otras formas estéticas de representación irrumpen en el escenario estatal. La ceremonia de inauguración del Museo el 11 de enero de 2010 constituyó un caso paradigmático al respecto. A diferencia de los museos del Holocausto, que tienen como uno de sus principios fundamentales la imposibilidad de la celebración, el Museo de la Memoria chileno sí contiene un carácter festivo indisoluble cifrado en su conmemoración de la democracia y el consenso. De ahí la comitiva de expresidentes que escoltaron a Bachelet en el acto de inauguración. No obstante, tal celebración se vio tambaleada por fuerzas mnemotécnicas que apuntaban en diferentes direcciones. De un lado, la presencia de Mario Vargas Llosa entre los invitados provocó el abucheo de una parte del público que le recriminó su ambivalente postura de apoyo a la candidatura de Sebastián Piñera, de una parte, y su cooperación con Bachelet, de otra; su consenso radical en un modelo político turnista y económico neoliberal de país aún no aceptado por una parte de la ciudadanía, en este caso probablemente más afín a la Concertación.

De otro lado, mientras la presidenta Michelle Bachelet pronunciaba su discurso, dos activistas mapuches, Catalina Catrileo y Ana Vergara Toledo, se subían a un poste de iluminación, entre la multitud asistente y cerca del 
escenario donde se encontraba Bachelet, e interrumpieron el acto. Catrileo, señalando directamente a Bachelet con el dedo índice, y lanzado octavillas al aire, gritaba lo siguiente: "Soy hermana de Matías Catrileo, asesinado en democracia en tu gobierno, Michelle Bachelet, por luchar por los derechos de las tierras mapuches. Es asesinado, y el paco [policía] sigue trabajando." Bachelet contestó: "Pido respeto para todas estas familias que, como ustedes, piden justicia." ${ }^{\prime 2}$

Cataliana Catrileo es, efectivamente, hermana de Matías Catrileo, estudiante de agronomía en Temuco asesinado por el carabinero Walter Ramírez Inostroza el 3 de enero de 2008, a los veintidós años, cuando participaba en la toma del fundo Santa Margarita, en el contexto del reclamo de tierras del conflicto mapuche. Catrileo se convirtió en símbolo de la lucha mapuche, y en una conmemoración por su muerte, cinco años después, era asesinado el matrimonio de Vivianne Mackay y Werner Luchsinger, propietarios de Santa Margarita, durante una nueva toma de la misma por parte de grupos mapuches. El relato de este conflicto, del cual el caso de Catrileo y los Mackay-Luchsinger es tan sólo un episodio, no tiene cabida en la muestra permanente de un Museo que se presenta como de la Memoria y los Derechos Humanos. A pesar de la universalidad de su nominación, la muestra permanente del Museo cancela otros activismos políticos y se restringe al caso concreto de la dictadura, como periodo finiquitado. La aparición de otros conflictos nacionales que involucran los derechos humanos, algunos tan esenciales como el mapuche, sólo se produce como fuga de una memoria subterránea pero palpitante, que no entra en el Museo, pero irrumpe en su puesta en escena con dedo acusador.

Con el tiempo, no obstante, el Museo ha incorporado esa crítica. Si bien la muestra permanente se mantiene estable, a través de las exposiciones temporales se va dando cabida a otras memorias. Por ejemplo, el 24 de noviembre de 2012, el cantante de hip hop mapuche Gonzalo Lunko estrenaba su disco Inche ta Luanko en la misma explanada del Museo donde Catrileo increpó a Bachelet durante la inauguración. En otras ocasiones, el conflicto mapuche se ha incorporado al trabajo de memoria general del Museo, relacionándolo con la dictadura, como en el caso de las sesiones de cortometrajes sobre "Las diversas dificultades que enfrentaron los pueblos originarios durante la dictadura", organizadas para el verano de 2015. Asimismo, el Museo se ha abierto a otros conflictos de América Latina, por ejemplo con la exposición "La calle de las penas / Viajes por América Latina (1975-1995)", que pudo visitarse entre junio y noviembre de 2014. 
SECRETO PÚBLICO: EL ALLENDISMO

Los memoriales se han vuelto peligrosos en la medida en que la ambigüedad de sus cruces aisladas, de sus paredes desnudas o de sus formas escultóricas mínimas apuntan centrífugamente hacia diversos puntos. Caso paradigmático es el de Londres 38. La decisión curatorial de concebir Londres 38 como espacio cero, interviniendo sólo para dejar cada habitación de la casona expuesta, sin ningún objeto, vaciada, lo ha convertido en un espacio de la memoria particularmente ambivalente. En el invierno de 2013 una exposición fotográfica mostraba las manifestaciones del movimiento estudiantil por las calles de Santiago. Retratos de estudiantes tomando la ciudad y elevando pancartas contra el sistema económico neoliberal y por una educación pública, gratuita y de calidad. Era fácil ver banderas comunistas entre los manifestantes, pues algunos de sus líderes pertenecían o eran simpatizantes de este partido. La imagen de esos jóvenes de hoy expuesta en el espacio donde se torturó a la generación de sus padres que abogaban asimismo por un modelo de país alternativo a las lógicas del mercado mundial.

Un aspecto que generalmente queda fuera de las discusiones en torno al Museo es cuál es la participación de este en esas lógicas. Abordar tal tema supone subvertir los límites cronológicos simples impuestos por el Museo, y leerlo desde más allá de 1973, esto es, abriendo el camino a la recuperación de la memoria de las víctimas, no en cuanto víctimas, sino en cuanto activistas y militantes; y hasta más acá de 1990, concretamente hasta las manifestaciones del movimiento estudiantil como aparición del disenso en el sentido de Rancière, es decir, como distintas opciones e interpretaciones compitiendo en el marco de lo sensible: la educación pública vuelve a proponerse como opción, irrumpiendo radicalmente en el debate público. Asimismo, como repetición contemporánea del barullo allendista y el golpe que muestra el Museo en las escaleras de acceso a las salas de exhibición.

El Museo se vio obligado a cerrar sus puertas durante meses debido al terremoto que tuvo lugar apenas unas semanas después de su apertura, constituyendo una metáfora irónica de la propia precariedad del relato estatal de la memoria planteado en el Museo. Esto hubiera quedado en un episodio desgraciado más de los muchos que produjo el terremoto si no hubiera revelado una nueva dimensión del desgaste del lenguaje oficial de la memoria. El seísmo devolvió la categoría de desaparecido al debate público, así como la idea de reconstrucción nacional, recurrente en la historia chilena dada sus abundantes catástrofes naturales, pero que también nutrió de forma primordial el discurso de la transición democrática (Richard, Crítica 11). Así pues, durante los meses de 
inauguración del Museo, coincidentes con la toma del poder de la derecha, el lenguaje oficial de la memoria experimenta su punto de vaciamiento más extremo.

La crítica, por su parte, ha entendido que su empresa intelectual debía consistir precisamente en la mostración de ese vaciamiento y la acuñación de un lenguaje diferente desde el que interpelar al Estado. Es notable en este sentido la evolución en los trabajos de Richard. Sus textos parten de una retórica de la memoria del Holocausto en los 90 y principios del 2000 hasta producir una historización y una crítica de esas políticas y prácticas de la intelectualidad en su texto de 2010. En este último, además, ya apunta de alguna forma a la insuficiencia del relato de la víctima total, los derechos humanos, la justicia y la reconciliación, y establece vías para seguir nuevas sendas. Esas vías, aún de forma incipiente, poseen una dimensión político-económica en cierta medida inédita en los debates de la memoria anteriores. Por ejemplo, al decir: "Son muchas las líneas discontinuas, las roturas y torceduras de una memoria no plena, disgregada y convulsiva que revientan el bloque estático de una representación homogénea de la historia y sus víctimas" (Crítica 19). La víctima, por tanto, requiere una historización e individuación que hasta ahora le ha sido negada.

Asimismo, es crucial cómo incorpora al debate chileno la distinción establecida por James Young entre monumentos y contra-monumentos. La cita que Richard recupera de Young es larga, pero queda aquí reproducida en su integridad porque es altamente significativa:

Uno de los resultados más interesantes del enigma sobre el memorial de Alemania ha sido el advenimiento de lo que llamaré "contra-monumentos": espacios memoriales concebidos para desafiar las premisas del monumento. Para la nueva generación de artistas alemanes la posibilidad de que la memoria de hechos tan graves pueda ser reducida a exposiciones de arte o pathos vulgar resulta intolerable. Recusan desdeñosamente los supuestos y formas tradicionales del arte memorial público; espacios que consuelan a los espectadores o redimen los hechos trágicos... Estos artistas temen sobre todo que si alentamos la idea de que los monumentos hagan por nosotros el trabajo de la memoria, nos volveremos entonces mucho más olvidadizos... El contramonumento nos recuerda que es posible que el mejor memorial alemán al período fascista y a sus víctimas no sea un memorial sino el deber siempre irresuelto acerca de qué clase de memoria preservar, cómo hacerlo, en nombre de quién y para qué fin. (Crítica 93; énfasis de Richard)

Este reclamo por una nueva monumentalidad de la memoria ha de buscar contraponerse no sólo al relato de la memoria oficial del Estado, sino a la 
sobrecodificación de la máquina liberal (Richard, Crítica 25). El marco para leer esta posibilidad del contra-monumento, o incluso del contra-museo, sería el de una comprensión de las industrias de la memoria, no a la forma planteada por Kerwin L. Klein, como desconfianza y competición con los estudios históricos, sino con la producción de un mercado de la memoria frecuentemente impulsado por el propio Estado.

Durante años, el Museo ha estado situado en el número 1 de las atracciones más visitadas y comentadas en TripAdvisor, de un total de 146 atracciones. Es publicitado en todos los folletos informativos de la ciudad y se ha convertido, sin lugar a dudas, en uno de los reclamos turísticos más exitosos de la ciudad. La localización del Museo es parte de un plan urbanístico que pretende revitalizar la comuna Quinta Normal en Santiago a través de su re-significación y la marca de barrio-museo. En este respecto, rompe con la lógica de los espacios de la memoria, esto es, con la vinculación de los memoriales a los lugares donde se perpetraron actos de represión. De esta forma, el Museo resignifica asimismo el mapa de la memoria de Santiago, produciendo una dislocación: se propone a modo de leyenda que da sentido al resto del mapa urbano de la memoria y muy en particular los signados como espacios de la memoria: el Estadio Nacional, Londres 38 y Villa Grimaldi, entre ellos. Es decir, para acceder al relato oficial del Estado que da sentido a esos espacios sacralizados de la memoria hay que salir de ellos, dislocarse, pues la clave que los descifra se encuentra en el extremo de ese mapa de la memoria, en el barrio Matucana de la comuna Quinta Normal.

Quinta Normal es una comuna al Este de la ciudad, cerca de la estación central, cuya relación con la memoria de la dictadura es si no vaga, al menos sí más ligera que muchos otros espacios de la ciudad, carente del simbolismo de otros distritos. El Museo se encuentra en terrenos municipales donde, en principio, no hay una historia de uso con potencial simbólico por parte de los gobiernos pinochetistas ni las fuerzas militares. En los últimos años, no obstante, una de las arterias principales de la comuna, la calle Matucana, ha vivido un profundo proceso de gentrificación a través de la construcción de varios recintos museísticos y archivísticos muy próximos entre sí. En un barrio donde ya había museos como el de Historia Natural (MNHN, fundado en 1830), el de Educación Gabriela Mistral (MEGM, 1941), el de Arte Contemporáneo (MAC, 1947) y el Ferroviario (1984), en los últimos años han abierto, concentrados en muy pocas manzanas, el Centro Cultural Matucana 100 (2001), la Biblioteca de Santiago (2005) y el Museo de la Memoria y los Derechos Humanos (2010). Todas estas instituciones públicas son prácticamente colindantes, con lo que la densidad de espacios culturales es muy elevada. 
El mapa de la memoria de Santiago es sometido a las lógicas del proceso neoliberal que estipula para cada barrio una identidad-marca para convertirlo en zona de explotación turística. El Museo chileno es también un espacio concebido para exportar una imagen-país de Chile como reconciliado con su violento pasado reciente. La seudo-transparencia del prisma que contiene las exhibiciones apunta hacia el fin de las políticas del secreto del archivo, donde al reclamo del derecho a la mirada, como plantea Cristián Gómez-Moya, es sustituido por un voyerismo truncado hacia un objeto que anuncia su autopsia fácil, pero que devuelve una opacidad de distinto cuño. El Museo combina seudo-transparencia espectacular con estética de catacumbas, en la que los archivos siguen soterrados, sirviendo de pilares a una exhibición hermética en lo espacial y en lo cronológico que busca una trayectoria monocarril hacia el presente: la reafirmación del consenso.

Un museo definido por lo que queda fuera, por las lógicas en las que no se inserta, por lo no museizable: el allendismo y sus recuperaciones contemporáneas. Marco Antonio de la Parra proponía en 2000 una lectura de Chile como un país doblemente decapitado: de un lado, por el cerebro dañado de un Pinochet senil; de otro, por el cerebro baleado de Allende en La Moneda. Chile con un daño cerebral del que nadie se responsabiliza. En este contexto, el Museo es un eslabón clave en la cadena de equivalencias de las políticas estatales de la memoria y el olvido para dar cuenta del primero y seguir posponiendo la confrontación con el segundo.

Princeton University

NOTAS

1 Esta investigación ha sido posible gracias a las becas de verano para estadías en el extranjero del Programa en Estudios Latinoamericanos (PLAS) de la Universidad de Princeton.

2 Ligeramente distinto es el Museo Memoria y Tolerancia, que abrió sus puertas en octubre de 2010 en la Ciudad de México. La nomenclatura es relevante y será comentada en secciones posteriores de este estudio. Aunque todos los museos hacen referencia a valores universales como la memoria, la tolerancia o los derechos humanos, el mexicano es el único cuya colección no está estructurada en torno a un relato eminentemente nacional e históricamente delimitado, sino que tiende a cierta universalidad, aunque con énfasis en la memoria del Holocausto. 
3 En un texto del mismo año de la inauguración del Museo (2010), Nelly Richard produjo una de las lecturas críticas más penetrantes de este espacio: disiente de las prácticas curatoriales del Parque por su didactismo ingenuo y por la estatización ornamental de sus ruinas. Asimismo, se muestra en desacuerdo con el afán organizador y simplista del lugar: "la espacialidad homogénea y la geometría de Villa Grimaldi convierten en un ordenado campo de visión lo que fue una desgarrada textura de la experiencia, descorporizando así la materia vivencial del recuerdo cuyas hondas fracturas de la subjetividad no tienen cómo reconocerse en esta serena nivelación de planos sin accidentes que se quiere facilitadora de una distendida experiencia de paseos" (Crítica 255).

4 Cito una de sus primeras intervenciones sistemáticas en inglés sobre el concepto de lieux de mémoire. Su investigación completa fue publicada bajo el título Les Lieux de mémoire por Gallimard en 1984-1986.

5 La amplitud geográfica que estudia Huyssen en esta obra - Berlín post-1989, Buenos Aires post-dictadura y New York post-11 de septiembre - es representativa de lo global del fenómeno.

6 Para más información en torno a la recuperación de Villa Grimaldi por parte de la Asamblea Permanente por los Derechos Humanos de Peñalolén y La Reina.

7 El Museo Judío de Berlín es relativamente diferente por dos razones: i) por su mayor amplitud historiográfica, dado que su muestra permanente no se limita a un evento particular, como el Holocausto, sino que recoge de forma abarcadora la historia del judaísmo; ii) por su propia historia institucional, puesto que fue inaugurado en 1933 en una localización diferente a la actual, y cerrado por el régimen nazi en 1938, hasta su reapertura en 1978. El edificio actual de Daniel Libeskind fue terminado en 1999 y abierto al público en 2001. Aun así, y teniendo en cuenta el año de su apertura original, 1933, el Museo Judío de Berlín puede considerarse dentro de la crisis memorística y la imposición historiográfica estudiada por Nora. La cuestión es debatible, no obstante, a partir de la lectura de la represión nazi como una intervención en la memoria viva del pueblo judío o como una reconstrucción historiográfica en pos de una reconfiguración nacional que requiere la identificación de un enemigo exterior internalizado.

8 Entre esas certezas se halla la del número de víctimas. En este sentido sí hubo discusión, no sobre los términos cuantitativos, sino cualitativos: ¿qué tipo de víctimas se presentarían en el museo? ¿Sólo los judíos o todas las víctimas del Holocausto? La solución fue incluir a todas las víctimas pero sin desplazar a los judíos del centro, sin desjudizar el Museo-Memorial. Esto es relevante para el caso chileno, no tanto para el Museo en sí, que es más abierto a la hora de reconocer la incertidumbre sobre el número total de víctimas de la dictadura pinochetista, como con respecto a otros lugares de la memoria en Chile. Nelly 
Richard ha llamado la atención al respecto, al denunciar como en el memorial del Cementerio General de Santiago hay, junto a la placa conmemorativa con los nombres de los detenidos desaparecidos, un número determinado de nichos vacíos, como si fuese posible establecerse con nitidez hoy día cuál es el número de desaparecidos no identificados. A juicio de Richard, esta búsqueda de certeza es irrespetuosa y banal, e incide en los despropósitos de los responsables del Cementerio General como lugar de memoria, que ya cometieron el grave error de las identificaciones erróneas de los cadáveres enterrados en el Patio 29 (Crítica 257).

9 La selección del fragmento, con sus elisiones, corresponde al propio Moreiras, y lo respeto tal cual para no desvirtuar su argumento.

10 De acuerdo con entrevistas que llevé a cabo a sus responsables entre julio y agosto de 2013 .

11 Laclau usa la noción de significante vacío para explicar el funcionamiento del populismo. Los significantes vacíos son el repertorio de términos que aglutinan y articulan una serie de demandas sociales mucho más amplias y complejas. El líder populista es la aglutinación última de estos términos. Se trata, en definitiva, de una forma discursiva de creación del pueblo y la nación. En el caso del museo, se trata más que de un líder carismático (ya queda analizado el posicionamiento de Bachelet como historia de reconciliación), de un espacio arquitectónico y expositivo que aglutina una diversidad de memoriales regionales, municipales, comunitarios e individuales a través de un discurso narrativo-visual basado en significantes cuasi-vacíos como la memoria, los derechos humanos, la accesibilidad (los archivos de la dictadura accesibles para quien los solicite), la transparencia (enfatizada por el diseño del museo). Estos términos tan ambiguos son usados, igualmente, para fijar un discurso y constituir un pueblo ante una nueva transición, el retorno de la derecha al gobierno, en un marco democrático.

12 Puede verse aquí: https://www.youtube.com/watch?v=XvojvdoCvQY

OBRAS CITADAS

A ga m b en, gi orgi o. Homo Sacer. Sovereign Power and Bare Life. Trad. Daniel Heller-Roazen. Stanford: Stanford UP, 1998.

AREnd T, Hannah. Men in Dark Times. Nueva York: Harcourt Brace Jovanovich, 1968.

Benja min, walter. "Theses on the Philosophy of History". Illuminations. Ed.

Hannah Arendt. Trad. Harry Zohn. Schocken: New York, 1969: 253-264.

BERENBAUM, MiCHAEL. The World Must Know: the History of the Holocaust as Told

in the United States Holocaust Memorial Museum. Boston: Little Brown, 1993. 
DÉ OT TE, JEAn Lo U IS. Catástrofe y olvido. Las ruinas, Europa, el Museo. Santiago: Cuarto Propio, 2008.

GÓ M EZ-MOYA, CR IS T IÁN. Derechos de mirada: arte y visualidad en los archivos desclasificados. Santiago de Chile: Palinodia, 2012.

HIRSCH, MARIANNE. The Generation of Postmemory: Writing and Visual Culture After the Holocaust. Nueva York: Columbia UP, 2012.

hu YS S n, An DRE As. Present Pasts: Urban Palimpsets and the Politics of Memory. Standford: Stanford UP, 2003.

KLEIN, KERWIN LEE. "On the Emergence of Memory in Historical Discourse". Representation 69 (2000): 127-150.

laC la u, e rnest o. On Populist Reason. Nueva York: Verso, 2005.

LEACH, NEIL. Camouflage. Cambridge: MIT Press, 2006.

moreiras, Alb E r o. "El otro duelo: A punta desnuda (Postfacio)". Pensar en/la postdictadura. Eds. Alberto Moreiras y Nelly Richard. Santiago: Cuarto propio, 2001: 315-330.

NIETZSCHE, FRIEDRICH w. The Use and Abuse of History. Trad. Adrian Collins. Indianapolis: Bobbs-Morrill Educational Pub., 1957.

NoRA, PIERRE. Les Lieux de mémoire. París: Gallimard, 1984-1986.

-. "Between Memory and History". Memory and Counter-Memory. Número especial de Representations 26, (1989): 7-24.

ot A N O, R A F A El. Nueva crónica de la transición. Santiago: LOM ediciones, 2006.

parra, marco antonio de la. "Memoriay olvido". Políticas y estéticas de la memoria. Ed. Nelly Richard. Santiago: Cuarto Propio, 2000.

RANCiÈre, JA CQues. Dissensus: on Politics and Aesthetics. Londres/Nueva York: Continuum, 2010.

RENAN, ERNEST. Qu's est-ce qu'une nation? Et autres écrits politiques. París: Imprimerie nationale, 1996.

RICHARD, NELLY. "Introducción”. Pensar en/la postdictadura. Eds. Alberto Moreiras y Nelly Richard. Santiago: Cuarto propio, 2001: 9-20.

—. Crítica de la memoria (1990-2010). Santiago: Ediciones Universidad Diego Portales, 2010.

-. Políticas y estéticas de la memoria. Santiago: Cuarto Propio, 2000.

Stern, steve J. Reckoning with Pinochet. The Memory Question in Democratic Chile, 1989-2006. Book Three of the Trilogy: The Memory Box of Pinochet's Chile. Durham/Londres: Duke UP, 2010.

ta ussi G, micha l. Defacement: Public Secrecy and the Labor of the Negative. Stanford: Stanford UP, 1999.

younG, JAmEs E. "The Counter-Monument: Memory Against Itself in Germany Today". Critical Inquiry 18. 2 (1992): 267-296. 